J. Lake Sci.(湖泊科学), 2017, 29(2): 448-457

DOI 10. 18307/2017. 0221

(c) 2017 by Journal of Lake Sciences

\title{
抚仙湖沉水植物分布及其碳、氮和磷化学计量学特征”
}

\author{
李 威 ${ }^{1}$, 符 辉 $^{2}$, 曹 特 $^{3 * *}$, 张霄林 ${ }^{3}$, 钟家有 ${ }^{2}$, 倪乐意 ${ }^{3}$, 谢 平 $^{3}$, 焚后保 ${ }^{1}$ \\ (1: 南昌工程学院, 江西省退化生态系统修复与流域生态水文重点实验室,南昌 330099) \\ ( 2 : 江西省水利科学研究院, 江西省鄱阳湖水资源与环境重点实验室, 南昌 330029$)$ \\ (3: 中国科学院水生生物研究所东湖湖泊生态系统试验站, 武汉 430072)
}

\begin{abstract}
摘 要: 目前对于沉水植物碳 $(\mathrm{C})$ 、氮 $(\mathrm{N})$ 和磷 $(\mathrm{P})$ 化学计量学的野外研究主要集中在中营养或富营养化水体, 而对于贫 营养水体中沉水植物 C、 $\mathrm{N}$ 和 $\mathrm{P}$ 的积累特征研究较少. 基于对贫营养湖泊抚仙湖沉水植物的调查, 研究抚仙湖 9 种常见沉 水植物 $\mathrm{C} 、 \mathrm{~N}$ 和 $\mathrm{P}$ 化学计量学特征及其种间和种内差异. 结果表明: 1) 抚仙湖沉水植物主要分布在湖岸浅水区域, 分布水 深范围为 $0.5 \sim 14.0 \mathrm{~m}$, 平均分布水深为 $3.6 \mathrm{~m} ; 2$ ) 抚仙湖沉水植物地上部分 $\mathrm{C} 、 \mathrm{~N}$ 和 $\mathrm{P}$ 含量平均值分别为 $381.89 、 18.59$ 和 $2.13 \mathrm{mg} / \mathrm{g}, \mathrm{N}: \mathrm{P}$ 比平均值为 9.21 , 且 $\mathrm{C} 、 \mathrm{~N}$ 和 $\mathrm{P}$ 含量之间呈显著正相关;3) 抚仙湖沉水植物地上部分 $\mathrm{C} 、 \mathrm{~N}$ 和 $\mathrm{P}$ 含量及 $\mathrm{C}: \mathrm{N}$ 比和 $\mathrm{C}: \mathrm{P}$ 比值种间差异大于种内差异, 而 $\mathrm{N}: \mathrm{P}$ 比种内差异大于种间差异; 4) 抚仙湖沉水植物 $\mathrm{C}$ 含量和 $\mathrm{N}: \mathrm{P}$ 比平均值要 大于长江中下游一些富营养化湖泊的沉水植物, 抚仙湖沉水植物的生长可能潜在地受到 P 的限制.
\end{abstract}

关键词: 抚仙湖;沉水植物;分布;碳、氮、磷;化学计量学

\section{Distribution and carbon, nitrogen and phosphorus stoichiometric characteristics of sub- mersed macrophytes in Lake Fuxian}

LI $\mathrm{Wei}^{1}, \mathrm{FU} \mathrm{Hui}^{2}, \mathrm{CAO} \mathrm{Te}^{3 * *}$, ZHANG Xiaolin ${ }^{3}$, ZHONG Jiayou ${ }^{2}$, NI Leyi ${ }^{3}$, XIE Ping ${ }^{3}$ \& FAN Houbao ${ }^{1}$

(1: Jiangxi Key Laboratory for Restoration of Degraded Ecosystems \& Watershed Ecohydrology, Nanchang Institute of Technology, Nanchang 330099, P.R. China)

(2: Jiangxi Provincial Key Laboratory of Water Resources and Environment of Poyang Lake, Jiangxi Institute of Water Sciences, Nanchang 330029, P.R. China)

(3: Donghu Experimental Station of Lake Ecosystems, State Key Laboratory of Freshwater Ecology and Biotechnology, Institute of Hydrobiology, Chinese Academy of Sciences, Wuhan 430072, P.R.China)

Abstract: Field studies on carbon ( C ), nitrogen (N) and phosphorus (P) stoichiometry of submersed macrophytes commonly focus on mesotrophic or eutrophic waters, while plant stoichiometric characteristics in oligotrophic waters, which may be different from those in mesotrophic or eutrophic waters, are rarely involved. This work aimed to study the stoichiometric characteristics of submersed macrophytes in an oligotrophic lake, the Lake Fuxian, which is of great significance for comprehensive understandings of elemental biogeochemical cycles in lakes. We conducted a field investigation on the distribution of submersed macrophytes in the Lake Fuxian and measured the morphological and C, N and P stoichiometric characteristic of nine common submersed macrophyte species. Intraspecific and interspecific coefficients of variation $(\mathrm{CV})$ of stoichiometric characteristics of the sampled plants were also compared. The results revealed that submersed macrophytes distributed mainly in the shallow water depths (ranging from $0.5 \mathrm{~m}$ to $14.0 \mathrm{~m}$ with a mean value of $3.6 \mathrm{~m}$ ) in the Lake Fuxian. The mean values of $\mathrm{C}, \mathrm{N}$ and $\mathrm{P}$ contents in the aboveground parts of the nine species were $381.89,18.59$ and $2.13 \mathrm{mg} / \mathrm{g}$, respectively, with an average $\mathrm{N}: \mathrm{P}$ ratio of 9.21 . The $\mathrm{C}, \mathrm{N}$ and $\mathrm{P}$ contents of the plants were significantly positively correlated. Interspecific $C V$ of the $\mathrm{C}, \mathrm{N}$ and $\mathrm{P}$ contents and the $\mathrm{C}: \mathrm{N}$ and $\mathrm{C}: \mathrm{P}$ ratios were higher than the intraspecific $C V$, while intraspecific $C V$ was higher than the interspecific $\mathrm{N}: \mathrm{P}$ ratio. The $\mathrm{C}$ contents and $\mathrm{N}: \mathrm{P}$ ratios of sub-

* 江西省科技计划项目 (20151BAB214006,20161BBG70048)、水利部鄱阳湖水资源水生态环境研究中心开放基金项 目(ZXKT201511)、水利部科技推广项目(TG1520) 和国家水体污染控制与治理科技重大专项( 2012ZX07105-004) 联合资助. 2016-05-19 收稿;2016-07-07 收修改稿. 李威(1986 ), 男,博士;E-mail: liwei@ nit.edu.cn.

** 通信作者;E-mail: caote@ihb.ac.cn. 
mersed macrophytes in the Lake Fuxian were higher than most of those in the middle and lower reaches of the Yangtze River. The results indicated that the growth of submersed macrophytes in the Lake Fuxian was potentially limited by $P$.

Keywords: Distribution; carbon, nitrogen and phosphorus; stoichiometry; submersed macrophyte; Lake Fuxian

沉水植物是河流和湖泊中重要的初级生产力, 既能通过茎和叶吸收水柱中的营养, 也能通过根吸收底 泥中的营养, 对于维持湖泊生态系统结构、养分循环和清水稳态至关重要 ${ }^{[-2]}$. 近几十年来, 随着湖泊富营养 化加剧, 水体透明度下降,水体较低的光照强度和较高的营养水平及其交互作用产生的胁迫导致沉水植被 衰退严重 ${ }^{[3-4]}$. 要想成功修复沉水植被, 需要了解不同营养水平水体对沉水植物的生理生态方面的影响以及 沉水植物的适应性. 相关研究表明, 如果周围环境营养很充足, 水生植物能够积累超过它们所需要的营养物 质,一方面是储存营养物质, 另一方面也减小了环境过高的营养对植物的胁迫作用 ${ }^{[5-6]}$, 而植物在过度积累 营养物质的同时也消耗大量的碳水化合物, 不利于植物的生长 ${ }^{[3-4,6]}$.

碳 $(C)$ 、氮 $(N)$ 和磷 $(P)$ 是重要的生命元素 ${ }^{[7]}$, 植物 $C 、 N$ 和 $P$ 含量及其比值常广泛地被用来评估环境营 养元素的可利用性及其对植物生长的限制程度 ${ }^{[8-10]}$. 如 Koerselman 等 ${ }^{[8]}$ 的研究表明, 当湿生植物 N:P 比<14 时 $N$ 为生态系统限制因子, $N: P$ 比 $>16$ 时 $P$ 为限制因子; 而 Güsewell 等 ${ }^{[9]}$ 的研究表明只有当 $N$ 或 $P$ 为生态 系统限制因子时, 利用 $N: P$ 比来判定植物营养限制类型才是有效的. 目前国内对于沉水植物 $\mathrm{C} 、 \mathrm{~N}$ 和 $\mathrm{P}$ 的野 外研究主要集中在中营养或富营养化水体 ${ }^{[1-16]}$, 而这些水体的营养可能已经不是限制因子. 吴爱平等 ${ }^{\left[{ }^{[12]}\right.}$ 的 研究表明,水生植物能够富集水柱中过剩的营养; Cao 等 ${ }^{[3-4]}$ 的研究表明, 水柱高营养和低光照能够对沉水植 物产生胁迫, 使其积累过多营养, 消耗大量碳水化合物. 贫营养湖泊与富营养湖泊相反, 具有营养浓度低、透 明度高等特点, 所以贫营养湖泊中沉水植物 $\mathrm{C} 、 \mathrm{~N}$ 和 $\mathrm{P}$ 的积累特征有可能与中/富营养湖泊差异较大. 随着人 类活动的加剧, 湖泊富营养化的进程也越来越快, 湖泊沉水植被退化严重, 目前国内贫营养湖泊已经越来越 少了, 因此掌握贫营养湖泊沉水植物元素含量特征, 研究沉水植物在贫营养湖泊与富营养湖泊的营养代谢 差异, 已经显得十分必要和紧迫. 本研究基于典型贫营养湖泊——抚仙湖中常见的 9 种沉水植物的调查, 研 究其组织 $C 、 N$ 和 $P$ 化学计量学特征, 这有助于我们全面了解沉水植物元素循环及湖泊生物地球化学过程, 也有助于为富营养化湖泊沉水植被的修复提供理论支持.

\section{1 材料和方法}

\section{1 湖泊概况}

抚仙湖 $\left(24^{\circ} 21^{\prime} \sim 24^{\circ} 38^{\prime} \mathrm{N}, 102^{\circ} 49^{\prime} \sim 102^{\circ} 57^{\prime} \mathrm{E}\right)$ 是我国第二深水湖泊, 位于云南省中部, 是高原内陆断陷 湖, 属于珠江流域南盘江水系, 最深处约 $155 \mathrm{~m}$, 平均水深约 $89.6 \mathrm{~m}$, 面积约 $211 \mathrm{~km}^{2[17-18]}$. 近几十年来抚仙湖 水体营养水平有所提高, 其沉水植物总生物量和分布范围显著增加, 但相对于其它富营养湖泊, 抚仙湖仍属 于贫营养水平湖泊 ${ }^{[19-20]}$.

\section{2 采样方法与指标测定}

于 2012 年 8 月在抚仙湖全湖布设 17 个采样带 (图 1), 每个样带面积约为 $100 \mathrm{~m} * 100 \mathrm{~m}$, 每个样带在不 同水深处至少设置 18 个样方, 每个样方面积约为 $0.2 \mathrm{~m}^{2}$, 样方间隔约为 $10 \mathrm{~m}$. 采样工具为手动旋转镰刀式 沉水植物采集器, 采集沉水植物地上部分, 能够采集的最大深度为 $6.6 \mathrm{~m}$, 分布水深超过 $6.6 \mathrm{~m}$ 的沉水植物使 用彼得森采泥器采集. 每个样方采集到的沉水植物用湖水清洗掉附着物, 按种类分开, 每种植物取完整的地 上部分带回实验室处理. 每个样带用透明度盘测定水体透明度 (SD), 用水下照度计 (UWQ-192S 和 Li1400 , Li-Cor, Lincoln, NE) 测量水体表层、 $1 、 2$ 和 $3 \mathrm{~m}$ 处光照强度 (为避免风浪造成干扰过大, 每个水位光 照强度读取 5 个数值做重复), 各样带取表层以下 $5 \mathrm{~cm}$ 处水样带回实验室处理.

从现场采集回来的水样按照国标方法(SL88－2012, GB 11894-1989, GB 7479-1987, GB $11893-$ $1989)$ 处理并测定水体叶绿素 $\mathrm{a}(\mathrm{Chl} . \mathrm{a})$ 、总氮 $(\mathrm{TN})$ 、氨氮 $\left(\mathrm{NH}_{3}-\mathrm{N}\right)$ 、硝态氮 $\left(\mathrm{NO}_{3}^{-}-\mathrm{N}\right)$ 、总磷 $(\mathrm{TP})$ 和正磷酸盐 磷 $\left(\mathrm{PO}_{4}^{3-}-\mathrm{P}\right)$ 浓度等指标. 采集回来的每种沉水植物用超纯水仔细冲洗, 沥干浮水, 测量其株长并称量鲜重, 于 $105^{\circ} \mathrm{C}$ 烘箱中杀青 $30 \mathrm{~min}$, 然后调至 $80^{\circ} \mathrm{C}$ 烘干至恒重, 称量干重, 用植物研磨器磨成粉末. 沉水植物 $\mathrm{C} 、 \mathrm{~N}$ 含量采用元素分析仪 (Flash EA 1112 series, CE Instruments, Italy) 测定, P 含量采用浓硫酸-过氧化氢消解 
后, 采用钼锑抗分光光度法测定 ${ }^{[21]}$.

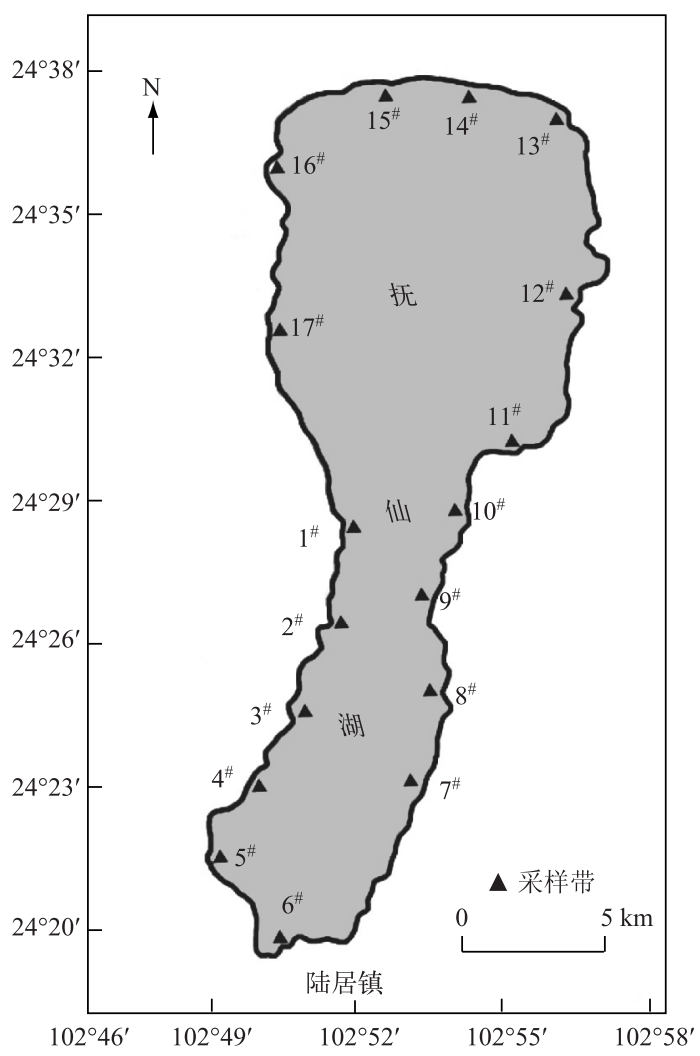

图 1 抚仙湖采样带分布示意

Fig.1 Distribution of the transects in Lake Fuxian

\section{3 统计分析}

为了便于比较, 本文所述沉水植物特指沉水维管束植物, 大型藻类轮藻由于大部分分布水深超过 $7 \mathrm{~m}$, 无法定量分析, 不包括在内; 蕰草由于主要生长在春季, 本调查 (8 月) 较少发现, 故也不作分析. 本研究选择 抚仙湖常见的沉水植物穗花狐尾藻 (Myriophyllum spicatum) 、扭叶眼子菜 (Potamogeton intortifolius)、穿叶眼 子菜 (Potamogeton perfoliatus)、苦草 (Vallisneria natans)、篦齿眼子菜 (Potamogeton pectinatus)、马来眼子菜 (Potamogeton malaianus)、微齿眼子菜 (Potamogeton maackianus)、金鱼藻 (Ceratophyllum demersum) 和轮叶黑 藻 (Hydrilla verticillata) , 样本量分别为 $18 、 11 、 19 、 18 、 15 、 11 、 11 、 13$ 和 11 , 共 127 个样本.

水体消光系数 $K_{\mathrm{d}}$ 计算方法: 以水深为 $x$ 轴, 以光照强度的自然对数为 $y$ 轴, 进行线性拟合, 得到回归方 程 $y=\mathrm{a} x+\mathrm{b}$, 消光系数 $K_{\mathrm{d}}=-\mathrm{a}$.

变异系数 $=$ 标准差 $/$ 平均值.

种内变异系数 $=(1 / n) \sum_{i=1}^{n} S D_{i}$. 其中 $n$ 为物种数, $i$ 为某物种, $S D_{i}$ 为物种 $i$ 的标准差, $M_{i}$ 为物种 $i$ 的平 均值.

种间变异系数 $=($ 所有物种平均值的标准差 $/$ 所有物种平均值 $)$.

沉水植物含水率 $=(100$ (1-干重/鲜重) $) \%$.

除特别说明外, 文中沉水植物 $C 、 N 、 P$ 含量均是指沉水植物地上部分 $C 、 N 、 P$ 含量. 均值之间的比较均经 过方差齐性检验和独立样本 $T$ 检验, 统计分析和作图软件为 SPSS 16.0. 


\section{2 结果}

\section{1 抚仙湖水体光学和营养特征}

抚仙湖的水体光照条件良好, 营养盐浓度也较低 (表 1). 水体平均透明度超过 $5 \mathrm{~m}$, 水体的消光系数均 值较小, 叶绿素 a 浓度也较低. 水体营养盐浓度按照《地表水环境质量标准》(GB 3838-2002) 划分, 处于 I 类和 II 类水之间.

表 1 抚仙湖水体光学和水化学指标

Tab.1 Light and nutrient status in the water column of Lake Fuxian

\begin{tabular}{rcccccccc}
\hline & $\begin{array}{c}\mathrm{SD} / \\
\mathrm{m}\end{array}$ & $\begin{array}{c}\mathrm{Chl.a} / \\
(\mu \mathrm{g} / \mathrm{L})\end{array}$ & $\begin{array}{c}K_{\mathrm{d}} / \\
\mathrm{m}^{-1}\end{array}$ & $\begin{array}{c}\mathrm{TN} / \\
(\mathrm{mg} / \mathrm{L})\end{array}$ & $\begin{array}{c}\mathrm{NH}_{4}^{+}-\mathrm{N} / \\
(\mathrm{mg} / \mathrm{L})\end{array}$ & $\begin{array}{c}\mathrm{NO}_{3}^{-}-\mathrm{N} / \\
(\mathrm{mg} / \mathrm{L})\end{array}$ & $\begin{array}{c}\mathrm{TP} / \\
(\mathrm{mg} / \mathrm{L})\end{array}$ & $\begin{array}{c}\mathrm{PO}_{4}^{3-}-\mathrm{P} / \\
(\mathrm{mg} / \mathrm{L})\end{array}$ \\
\hline 平均值 & 5.57 & 1.68 & 0.439 & 0.295 & 0.055 & 0.004 & 0.013 & 0.009 \\
标准差 & 0.82 & 1.10 & 0.089 & 0.188 & 0.006 & 0.001 & 0.017 & 0.004 \\
\hline
\end{tabular}

\section{2 抚仙湖沉水植物种类及其分布}

调查期间, 抗仙湖共采集到沉水植物 9 种 (不包括轮藻和菹草), 它们在各样带的分布较均匀 (表 2), 分 布水深范围为 $0.5 \sim 14.0 \mathrm{~m}$, 平均分布水深为 $3.6 \mathrm{~m}$. 各样方中, 轮叶黑藻最大分布深度为 $14.1 \mathrm{~m}$, 金鱼藻最大 分布深度为 $9.5 \mathrm{~m}$, 这 2 种沉水植物的平均分布深度也最大, 均为 $4.6 \mathrm{~m}$; 扭叶眼子菜、穿叶眼子菜和马来眼子 菜最大分布深度相对较小,平均分布水深约为 $2.4 \mathrm{~m}$.

表 2 沉水植物在抚仙湖各样带的分布

Tab.2 Occurrence of submersed macrophytes at different sampling transects in Lake Fuxian

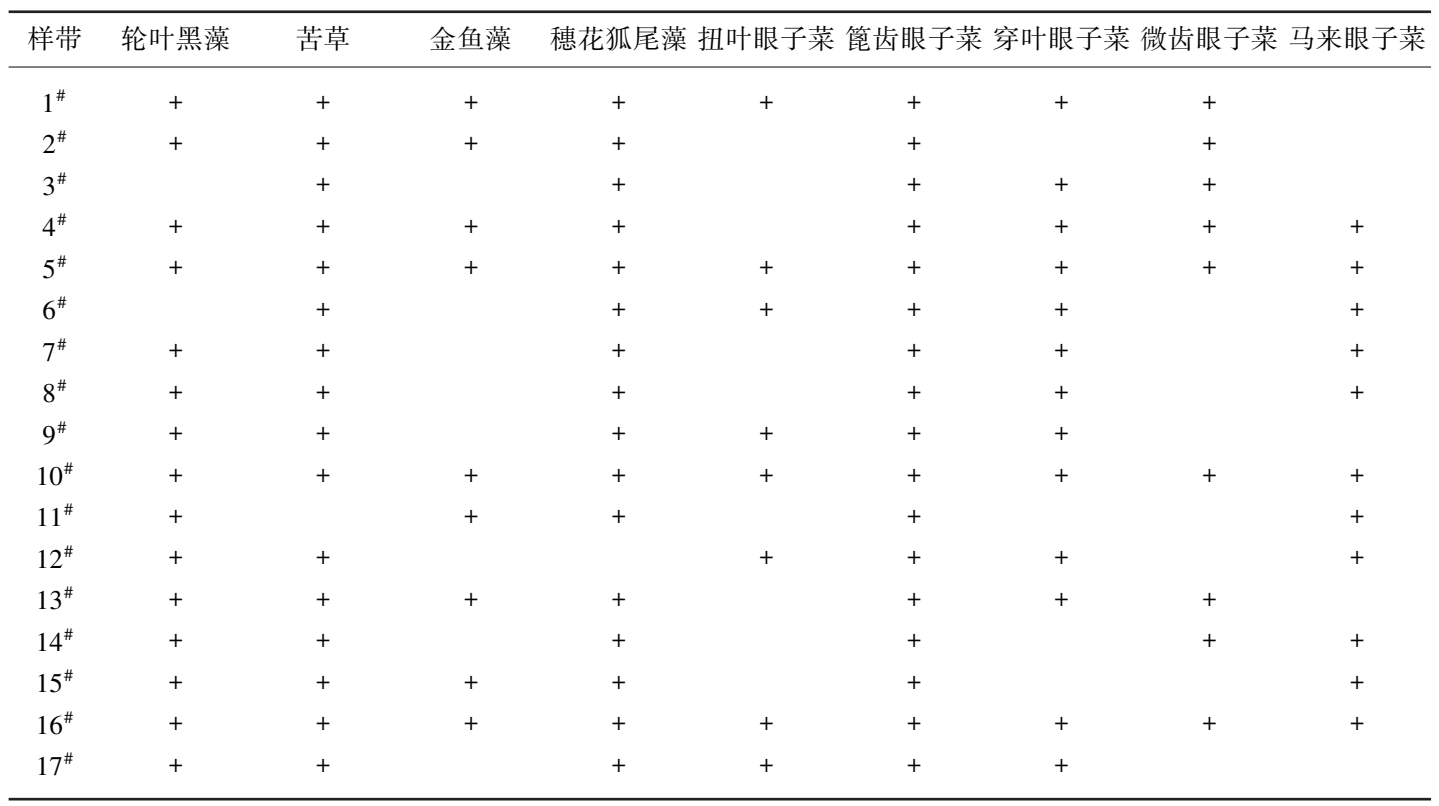

+表示在该样带分布.

\section{3 抚仙湖沉水植物形态学特征}

在采集到的 9 种沉水植物中, 苦草平均株高最小, 穿叶眼子菜平均株高最大, 各种沉水植物株长的差异 较大, 变异系数 (标准差与平均值之间的比值) 在 $8 \% \sim 80 \%$ 之间, 平均约为 $31 \%$; 金鱼藻的平均鲜重最大, 微 齿眼子菜的最小,穿叶眼子菜的平均干重最大, 轮叶黑藻最小.

金鱼藻和苦草含水率最高, 平均值超过 $94 \%$; 微齿眼子菜最小, 平均值约 $80 \%$; 各物种含水率变异较小, 
变异系数在 $0.3 \% \sim 5.8 \%$ 之间,平均变异系数不超过 $2 \%$ (表 3 ).

表 3 抚仙湖沉水植物各物种单株地上部分形态特征

Tab.3 Morphological characteristics of the aboveground parts of submersed macrophytes in Lake Fuxian

\begin{tabular}{lccccc}
\hline 沉水植物 & 样本数 & 株长 $/ \mathrm{cm}$ & 鲜重 $/ \mathrm{g}$ & 干重 $/ \mathrm{g}$ & 含水率 $/ \%$ \\
\hline 微齿眼子菜 & 11 & $234.0 \pm 30.8$ & $1.74 \pm 0.38$ & $0.35 \pm 0.14$ & $80.5 \pm 4.6$ \\
穗花狐尾藻 & 11 & $316.5 \pm 116.1$ & $10.99 \pm 4.43$ & $1.80 \pm 0.77$ & $83.4 \pm 2.1$ \\
篦齿眼子菜 & 4 & $193.3 \pm 15.9$ & $11.71 \pm 2.59$ & $1.06 \pm 0.22$ & $90.9 \pm 0.3$ \\
马来眼子菜 & 3 & $213.7 \pm 41.5$ & $6.57 \pm 1.06$ & 1.11 & 83.1 \\
金鱼藻 & 12 & $234.2 \pm 103.2$ & $18.85 \pm 6.91$ & $1.04 \pm 0.36$ & $94.2 \pm 1.0$ \\
轮叶黑藻 & 10 & $186.3 \pm 53.5$ & $4.20 \pm 1.42$ & $0.29 \pm 0.14$ & $92.7 \pm 1.4$ \\
苦草 & 15 & $108.1 \pm 32.7$ & $16.99 \pm 9.62$ & $0.94 \pm 0.47$ & $94.2 \pm 1.2$ \\
扭叶眼子菜 & 11 & $136.2 \pm 109.6$ & $8.23 \pm 7.66$ & $1.82 \pm 1.32$ & $83.0 \pm 1.0$ \\
穿叶眼子菜 & 17 & $317.0 \pm 75.9$ & $16.86 \pm 5.23$ & $1.94 \pm 0.64$ & $87.9 \pm 1.6$ \\
\hline
\end{tabular}

\section{4 抚仙湖沉水植物 C、N 和 P 含量及化学计量学特征}

在采集到的 9 种沉水植物中, 地上部分 $C 、 N 、 P$ 含量及其化学计量比均符合正态分布特征(图 2), $\mathrm{C}$ 含 量的平均变异系数最小, 仅有 $8.2 \%, \mathrm{~N}$ 居中, 为 $39.4 \%, \mathrm{P}$ 含量平均变异系数最大, 为 $46.5 \% ; \mathrm{C}: \mathrm{N}$ 比和 $\mathrm{C}: \mathrm{P}$ 比变异系数均较大, 都超过 $45 \%, \mathrm{~N}: \mathrm{P}$ 比变异系数相对较小, 为 $26.8 \%$ (图 2).
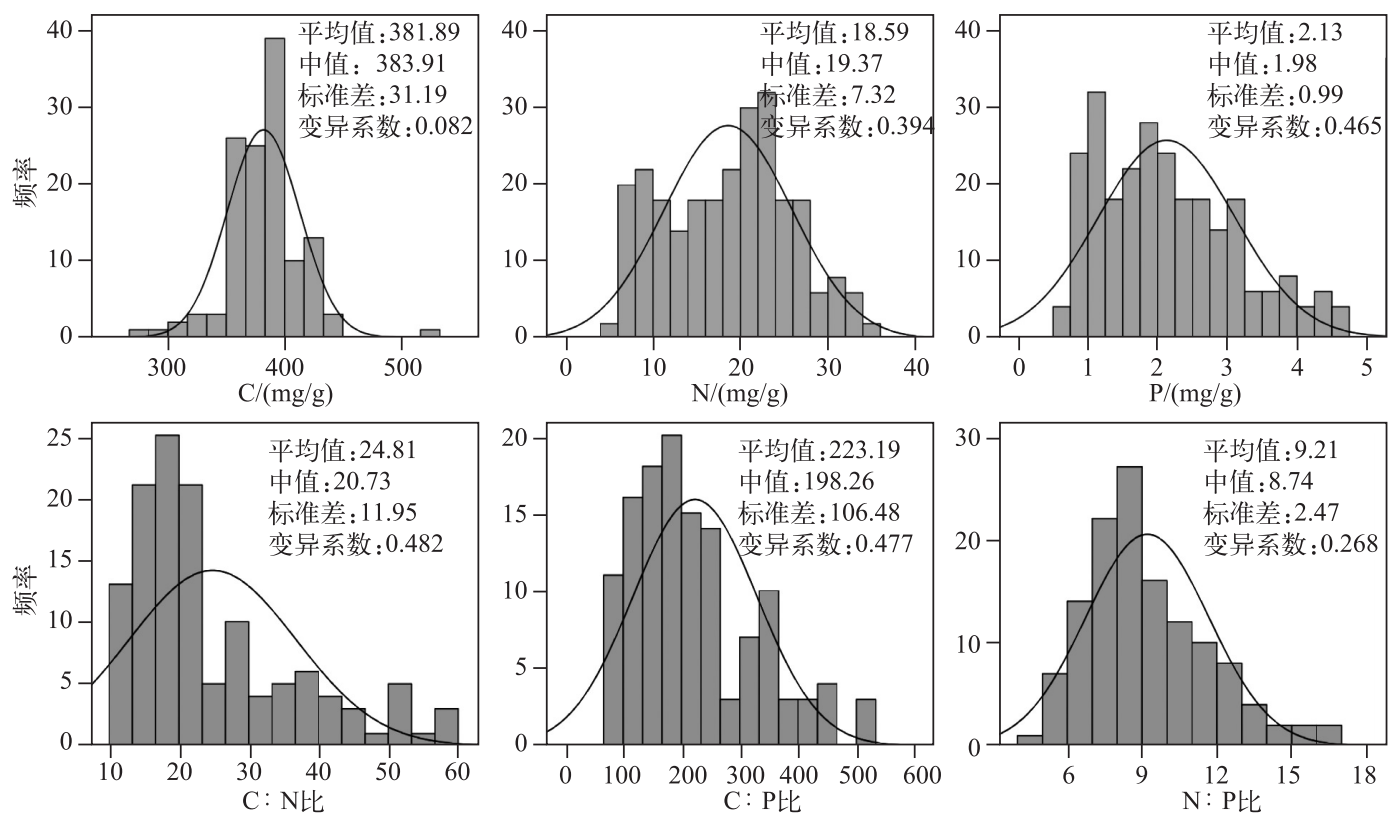

图 2 抚仙湖沉水植物地上部分 $\mathrm{C} 、 \mathrm{~N} 、 \mathrm{P}$ 含量及化学计量学特征频率分布直方图

(所用数据为所有个体数据, 图中所有平均值和中值均为质量比)

Fig. 2 Frequency distribution of aboveground C, N, P concentrations and their mass ratios of submersed macrophytes in Lake Fuxian

穗花狐尾藻 $\mathrm{C}$ 含量最小, 平均值为 $353.5 \mathrm{mg} / \mathrm{g}$; 微齿眼子菜 C 含量最高, 平均值达到 $424.8 \mathrm{mg} / \mathrm{g}$, 是穗花 狐尾藻的 1.2 倍; 眼子菜属的 5 种植物 C 含量均大于其它 4 种沉水植物 (平均值 $399.7 \mathrm{vs} 366.0 \mathrm{mg} / \mathrm{g}$ ) ( $T$ 检 验, $P<0.05)$.

轮叶黑藻 $\mathrm{N}$ 和 $\mathrm{P}$ 含量均最高, 分别为 31.1 和 $3.72 \mathrm{mg} / \mathrm{g}$; 穗花狐尾藻 $\mathrm{N}$ 和 $\mathrm{P}$ 含量最低, 分别为 8.66 和 
$1.08 \mathrm{mg} / \mathrm{g}$. 轮叶黑藻 $\mathrm{C}: \mathrm{N}$ 比和 $\mathrm{C}: \mathrm{P}$ 比最低; 而穗花狐尾藻 $\mathrm{C}: \mathrm{N}$ 比和 $\mathrm{C}: \mathrm{P}$ 比最高; 金鱼藻 $\mathrm{N}: \mathrm{P}$ 比最高, 为 11.4 ; 篦齿眼子菜 N:P 比最低, 为 7.03 ( 图 3).
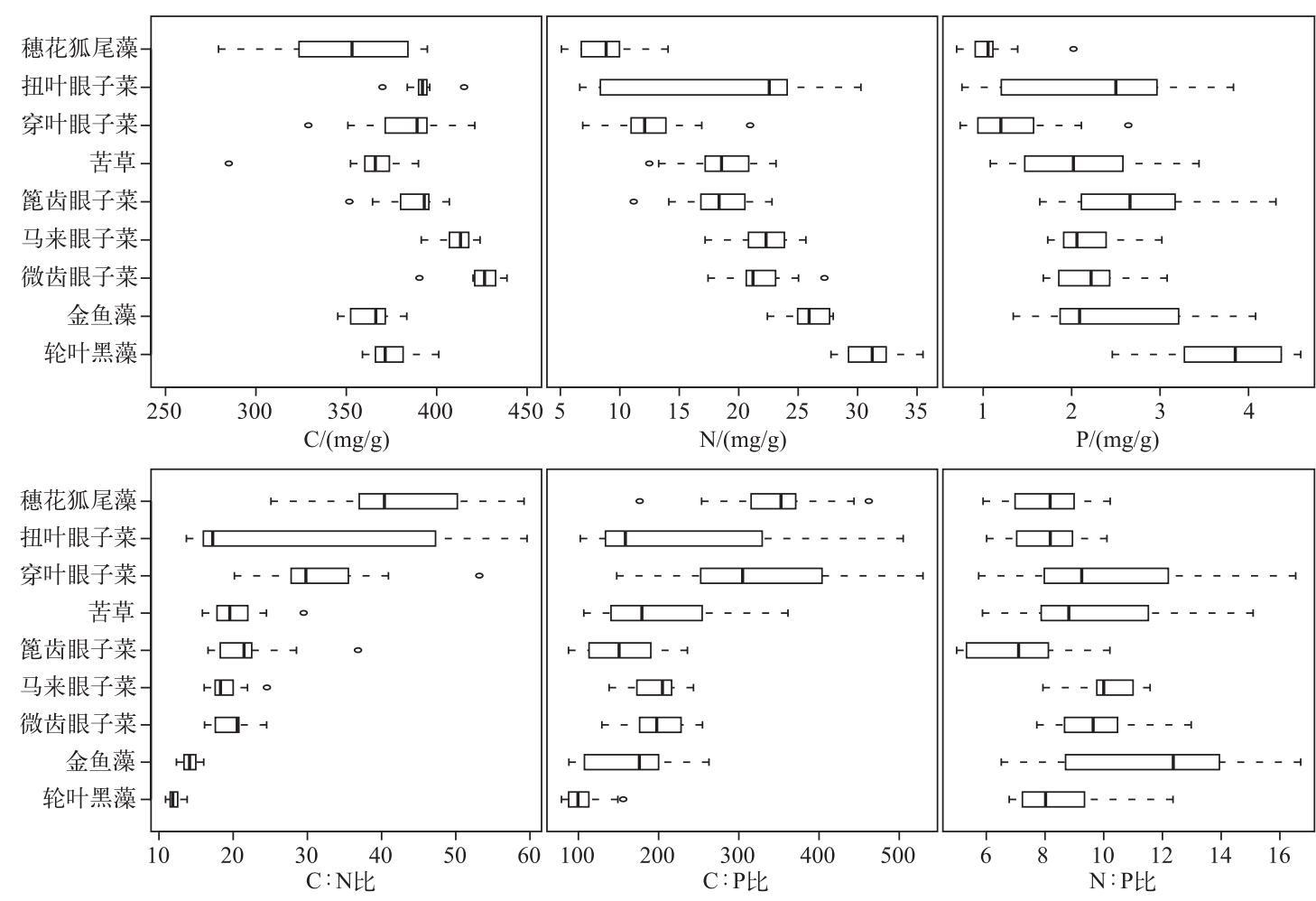

图 3 抚仙湖 9 种沉水植物地上部分 $\mathrm{C} 、 \mathrm{~N} 、 \mathrm{P}$ 含量及化学计量特征箱线图 (图中虚线的上下端代表最大值和 最小值,矩形的上下端代表上四分位数和下四分位数,横线为中位数,空心圆代表异常值)

Fig.3 Boxplots of C, N, P concentrations and their mass ratios of submersed macrophytes (aboveground parts) in Lake Fuxian( The top and bottom of dashed lines indicate maximum and minimum values. The top and bottom of boxes indicate upper and lower quartile. Lines in the boxes indicate median values. Empty circles indicate outliers)

\section{5 抚仙湖 9 种沉水植物化学计量学特征种内和种间差异}

抚仙湖沉水植物 $\mathrm{C} 、 \mathrm{~N}$ 和 $\mathrm{P}$ 含量种间差异大于种内差异, $\mathrm{C}: \mathrm{N}$ 比和 $\mathrm{C}: \mathrm{P}$ 比也是种间差异大于种内差异, 而 N:P 比则种内差异大于种间差异 (表 4).

表 4 抚仙湖 9 种沉水植物化学计量特征变异系数 (\%)

Tab.4 Coefficient of variation of stoichiometric characteristics of the nine submersed plants in Lake Fuxian

\begin{tabular}{lcccccc}
\hline & $\mathrm{C}$ & $\mathrm{N}$ & $\mathrm{P}$ & $\mathrm{C}: \mathrm{N}$ 比 & $\mathrm{C}: \mathrm{P}$ 比 & $\mathrm{N}: \mathrm{P}$ 比 \\
\hline 种内变异系数 & 5.09 & 19.38 & 30.32 & 20.56 & 31.24 & 21.17 \\
种间变异系数 & 5.86 & 34.07 & 34.27 & 41.30 & 36.18 & 14.76 \\
\hline
\end{tabular}

\section{6 抚仙湖沉水植物 $C 、 N$ 和 $P$ 含量及化学计量学相互关系}

沉水植物 $\mathrm{C} 、 \mathrm{~N}$ 和 $\mathrm{P}$ 含量之间呈显著相关 $(P<0.05), \mathrm{N}$ 与 $\mathrm{P}$ 含量的相关性要大于 $\mathrm{C}$ 与 $\mathrm{N}$ 含量的相关性, $\mathrm{C}$ 与 $\mathrm{N}$ 含量的相关性要大于 $\mathrm{C}$ 与 $\mathrm{P}$ 含量的相关性 (表 5). $\mathrm{N}$ 与 $\mathrm{P}$ 含量在沉水植物中紧密耦合, $\mathrm{N}$ 与 $\mathrm{P}$ 含量 相关系数达到 0.847(表 5),9 个物种之间 N 与 P 含量平均值也有较强的线性回归关系(图 4). 
表 5 抚仙湖沉水植物 $\mathrm{C} 、 \mathrm{~N}$ 和 $\mathrm{P}$ 含量及化学计量比之间的皮尔森相关系数

Tab.5 Pearson correlation coefficient among C, N, P concentrations and their mass ratios in the aboveground parts of submersed macrophytes in Lake Fuxian

\begin{tabular}{lcccccc}
\hline & $\mathrm{C}$ & $\mathrm{N}$ & $\mathrm{P}$ & $\mathrm{C}: \mathrm{N}$ 比 & $\mathrm{C}: \mathrm{P}$ 比 & $\mathrm{N}: \mathrm{P}$ 比 \\
\hline $\mathrm{C}$ & 1 & & & & & \\
$\mathrm{~N}$ & $0.338^{* * *}$ & 1 & & & & \\
$\mathrm{P}$ & $0.194^{*}$ & $0.847^{* * *}$ & 1 & & & \\
$\mathrm{C}: \mathrm{N}$ 比 & -0.163 & $-0.984^{* * *}$ & $-0.851^{* * *}$ & 1 & & \\
$\mathrm{C}: \mathrm{P}$ 比 & -0.021 & $-0.803^{* *}$ & $-0.985^{* *}$ & $0.838^{* *}$ & 1 & 1 \\
$\mathrm{~N}: \mathrm{P}$ 比 & $0.232^{* * *}$ & $0.180^{*}$ & $-0.370^{* *}$ & -0.144 & $0.418^{* * *}$ & 1 \\
\hline
\end{tabular}

表中数据为对 9 个物种所有样本数据的分析, 所有数据经对数转换后再进行相关分析; * 代表 $P<0.05, * *$ 代表 $P<0.01$.

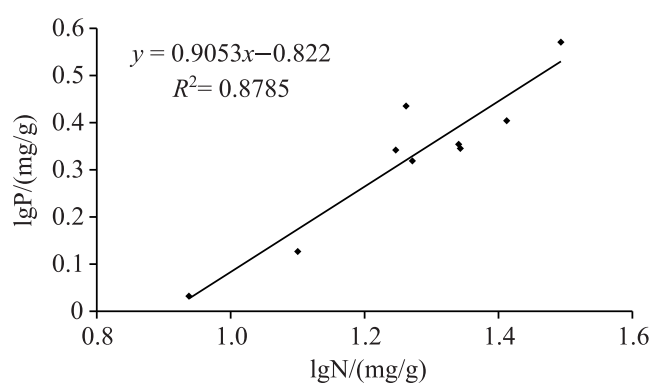

图 4 抚仙湖 9 种沉水植物地上部分 $N$ 、 $\mathrm{P}$ 含量散点图 (所有数据经过对数转换)

Fig.4 Scatter diagrams between $\mathrm{N}$ and

$\mathrm{P}$ contents in the aboveground parts of 9 submersed macrophyte species in Lake Fuxian (All data were log-transformed)

\section{3 讨论}

\section{1 抚仙湖沉水植物 C、N、P 含量及其化学计量特征}

抚仙湖 9 种沉水植物地上部分 $\mathrm{C}$ 含量平均值为 $381.89 \mathrm{mg} / \mathrm{g}$, Xing 等 ${ }^{[16]}$ 对长江中下游 24 个湖泊 12 种 沉水植物的研究表明, 沉水植物 C 含量平均为 325.72 $\mathrm{mg} / \mathrm{g}$, 表明抚仙湖大部分沉水植物 $\mathrm{C}$ 含量要显著高于 长江中下游一些湖泊的沉水植物 $(T$ 检验, $P<0.05)$. 长 江中下游湖泊大多是中营养和富营养湖泊, 其营养浓度 要远远高于贫营养的抚仙湖, 而透明度则远远低于抚仙 湖.Cao 等 ${ }^{[3]}$ 和 Zhang 等 ${ }^{[4]}$ 的研究表明, 水体中低光照和 高营养对沉水植物有很严重的胁迫作用, 沉水植物为了 缓解水体氨氮浓度过高对植物产生的毒性,把体内积累 的有毒的铵态氮转化成无毒氨基氮, 这个过程同时消耗 了大量碳水化合物, 水体低光照和高营养的长期作用可

能导致了长江中下游湖泊沉水植物的 $\mathrm{C}$ 含量低于抚仙湖沉水植物. 此外, 本研究还发现, 眼子菜属植物 $\mathrm{C}$ 含 量要高于其它属的植物, Xing 等 ${ }^{[16]}$ 的研究也表明马来眼子菜的 C 含量要高于其它植物, 这可能和眼子菜属 植物木质素含量高于其它沉水植物有关 ${ }^{[22]}$, 也说明沉水植物 $\mathrm{C}$ 含量的种间和属间差异也很大.

抚仙湖沉水植物地上部分 $\mathrm{N} 、 \mathrm{P}$ 含量分别为 18.59 和 $2.13 \mathrm{mg} / \mathrm{g}, \mathrm{N}$ 含量大于 Xing 等 ${ }^{[16]}$ 报道的长江中下 游湖泊沉水植物 $\mathrm{N}$ 含量, 也大于胡伟芳等 ${ }^{[23]}$ 报道的中国主要湿地植被 $\mathrm{N}$ 含量; 而 $\mathrm{P}$ 含量小于长江中下游沉 水植物的 $\mathrm{P}$ 含量 ${ }^{[16]}$, 这导致抚仙湖沉水植物 $\mathrm{N}: \mathrm{P}$ 比大于部分长江中下游湖泊沉水植物, 表明抚仙湖沉水植 物可能潜在地受到 $\mathrm{P}$ 的限制, Xing 等 ${ }^{[16]}$ 的研究中长江中下游湖泊水体 $\mathrm{N}: \mathrm{P}$ 比约为 12.3 , 远小于抚仙湖水体 $\mathrm{N}: \mathrm{P}$ 比 (为 22.7), 也部分地验证了这一假设. 不过本研究抚仙湖沉水植物 $\mathrm{N}: \mathrm{P}$ 比为 9.21 , 按照 Güsewell \& Koerselman ${ }^{[9]}$ 的阈值判断为 $\mathrm{N}$ 限制, 可能与实际情况不符, 沉水植物 $\mathrm{N}$ 和 P 限制的阈值目前仍不是很清楚, 需要进一步研究. 导致这些地区水生植物 $\mathrm{N}$ 和 P 含量不同有许多原因, 如环境营养浓度、气候、物种组成、功 能群和生长阶段等 ${ }^{[24-26]}$, 此外测量的方法、精度和样本量对结果影响也很大.

抚仙湖沉水植物 $\mathrm{C} 、 \mathrm{~N}$ 和 $\mathrm{P}$ 含量之间呈显著正相关, 表明这 3 种元素在植物新陈代谢及生物化学过程中 具有重要的耦合关系, 其中 $\mathrm{C}$ 与 $\mathrm{N}$ 含量及 $\mathrm{C}$ 与 $\mathrm{P}$ 含量的相关性要小于 $\mathrm{N}$ 与 $\mathrm{P}$ 含量的相关性, 表明 $\mathrm{C}$ 作为植 物组织中的结构物质随营养物质 $\mathrm{N}$ 和 $\mathrm{P}$ 含量的变化较小, 并且 $\mathrm{C}: \mathrm{N}$ 比与 $\mathrm{N}$ 含量及 $\mathrm{C}: \mathrm{P}$ 比与 $\mathrm{P}$ 含量呈显著 负相关, $\mathrm{C}: \mathrm{N}$ 比和 $\mathrm{C}: \mathrm{P}$ 比均与 $\mathrm{C}$ 含量无显著相关性.

\section{2 抚仙湖沉水植物 C、N、P 化学计量学种内和种间差异}

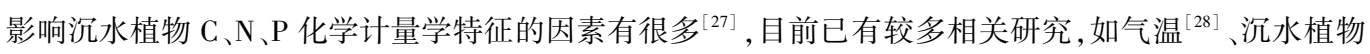
生长的水位 ${ }^{[29-30]}$ 、季节 ${ }^{[31]}$ 、不同器官 ${ }^{[26]}$ 等, 本研究在采样时尽量避免这些因素的影响, 然而沉水植物 $C 、 N 、 P$ 
化学计量学特征仍表现出较大的种内和种间差异. 其中 $\mathrm{P}$ 含量和 $\mathrm{C}: \mathrm{P}$ 比种内和种间差异都很大, 变异系数 超过 30\%, N 和 C: $\mathrm{N}$ 比种间差异也超过了 30\%. 这表明还有其他因素影响沉水植物 C、N、P 化学计量学特 征, 其中个体发育引起的变异也是一个不容忽视的因素, 如符辉等 ${ }^{[32]}$ 的研究表明, 微齿眼子菜个体发育引起 的变异占总变异的 5\% 76\%. 沉水植物种内和种间差异对于沉水植物多样性和功能稳定性有很重要的作 用, 能够增强其对多变水环境的适应能力 ${ }^{[33]}$.

\section{3 抚仙湖沉水植物发展趋势}

据戴全裕等 ${ }^{[34]}$ 的调查, $1980 \mathrm{~s}$ 抚仙湖沉水植物面积约为全湖面积的 $0.01 \%$, 总生物量约为 $400 \mathrm{t}$ (鲜重), 2005 年的调查表明 ${ }^{[19]}$, 抚仙湖沉水植物面积约占全湖面积的 $1.51 \%$, 总生物量约为 $19503 \mathrm{t}$ (鲜重), 这表明 抚仙湖沉水植物的分布面积和总生物量均显著提高,而在这期间, 抚仙湖的水体营养水平总体上也在不断 提高 ${ }^{[35-37]}$, 说明抚仙湖沉水植物仍处于不断发展期, 营养可能是限制抚仙湖沉水植物生长的重要因子.

沉水植物既能通过根吸收底泥中的营养物质, 也能通过叶和茎吸收水体中的营养物质 ${ }^{[38-39]}$, 许多研究 表明叶和根对沉水植物营养吸收的贡献取决于水体和底泥的相对营养状况 ${ }^{[39-40]}$. 由于抚仙湖周边某些地层 含有丰富的 P, 湖底沉积物的 P 含量也很高, 甚至高于许多富营养化湖泊 (如太湖) ${ }^{[41]}$. 因此抚仙湖中沉水 植物所需要的营养物质可能有很大一部分来自沉积物, 这也可能是抚仙湖沉水植物能够在贫营养水体中大 量生长的一个重要原因. 浮游植物由于主要吸收水体中的营养, 容易受到水体中 P 浓度的限制 ${ }^{[42]}$, 而抚仙 湖水体 $\mathrm{P}$ 浓度很低, 这有可能是抚仙湖中的浮游植物丰度很低的主要原因, 据刘镇盛等 ${ }^{[43]}$ 的调查, 抚仙湖中 的浮游植物以绿藻门占优势, 水体中的 $\mathrm{P}$ 是浮游植物生长的限制因子, 这可能是由于抚仙湖底质中的 $\mathrm{P}$ 活 性低、释放速度较慢的缘故. 沉水植物对底泥中的营养具有一定的㬌吸作用, 如 Smith 等 ${ }^{[44]}$ 的研究表明, 穗 花狐尾藻的根是 $\mathrm{P}$ 吸收的主要器官, 植物体内大部分的 P 从根部转运到枝叶, 所以穗花狐尾藻在底泥营养 盐释放到水体的过程中起很大作用. 近年来, 抚仙湖水体呈富营养化趋势, 有可能改变水体的理化环境, 从 而增加沉积物 P 的释放风险. 并且抚仙湖沉水植物生物量的增加也可能加速沉积物中 $\mathrm{P}$ 的释放, 应引起注 意并加强这方面的研究.

致谢: 感谢宋拿、何亮、朱天顺、袁昌波、摆晓虎等在野外采样给予的帮助.

\section{4 参考文献}

[ 1 ] Barko JW, Gunnison D, Carpenter SR. Sediment interactions with submersed macrophyte growth and community dynamics. Aquatic Botany, 1991, 41(1-3) : 41-65. DOI: 10.1016/0304-3770(91)90038-7.

[ 2 ] Scheffer M, Redelijkheid MR, Noppert F. Distribution and dynamics of submerged vegetation in a chain of shallow eutrophic lakes. Aquatic Botany, 1992, 42(3) : 199-216. DOI: 10.1016/0304-3770(92)90022-B.

[ 3 ] Cao T, Xie P, Ni LY et al. Carbon, nitrogen metabolism of an eutrophication tolerative macrophyte, Potamogeton crispus, under $\mathrm{NH}_{4}^{+}$stress and low light availability. Environmental and Experimental Botany, 2009, 68(1) : 74-78. DOI: 10. 1016/j.envexpbot.2008.10.004.

[ 4 ] Zhang M, Cao T, Ni L et al. Carbon, nitrogen and antioxidant enzyme responses of Potamogeton crispus to both low light and high nutrient stresses. Environmental and Experimental Botany, 2010, 68(1): 44-50. DOI: 10.1016/j. envexpbot. 2009.09.003.

[ 5 ] Demars BOL, Edwards AC. Tissue nutrient concentrations in freshwater aquatic macrophytes: High inter-taxon differences and low phenotypic response to nutrient supply. Freshwater Biology, 2007, 52(11) : 2073-2086. DOI: 10.1111/j.13652427.2007.01817.x.

[ 6 ] Cao T, Ni LY, Xie P et al. Effects of moderate ammonium enrichment on three submersed macrophytes under contrasting light availability. Freshwater Biology, 2011, 56(8) : 1620-1629. DOI: 10.1111/j.1365-2427.2011.02601.x.

[ 7 ] Elser JJ, Fagan WF, Denno RF et al. Nutritional constraints in terrestrial and freshwater food webs. Nature, 2000, 408: 578-580. DOI: $10.1038 / 35046058$.

[ 8 ] Koerselman W, Meuleman AFM. The vegetation N:P ratio: A new tool to detect the nature of nutrient limitation. Journal of Applied Ecology, 1996, 33(6) : 1441-1450. DOI: 10.2307/2404783.

[ 9 ] Güsewell S, Koerselman W. Variation in nitrogen and phosphorus concentrations of wetland plants. Perspectives in Plant Ecology, Evolution and Systematics, 2002, 5(1) : 37-61. DOI: 10.1078/1433-8319-0000022. 
[10] Tessier JT, Raynal DJ. Use of nitrogen to phosphorus ratios in plant tissue as an indicator of nutrient limitation and nitrogen saturation. Journal of Applied Ecology, 2003, 40(3) :523-534. DOI: 10.1046/j.1365-2664.2003.00820.x.

[11] Huang Liang, Wu Ying, Huang Jing et al. Distribution of C, N, P and $\delta^{13} \mathrm{C}$ in aquatic plants of some lakes in the middle Yangtze valley. Acta Geoscientica Sinica, 2003, 24: 515-518. [黄亮, 吴莹, 黄经等. 长江中游若干湖泊水生植物体内 C、N、P 及 $\delta{ }^{13}$ C 分布. 地球学报, 2003, 24: 515-518.]

[12] Wu Aiping, Wu Shikai, Ni Leyi. Study of macrophytes nitrogen and phosphorus contents of the shallow lakes in the Middle Reaches of Changiang River. Acta Hydrobiologica Sinica, 2005, 29: 406-412. [吴爱平, 吴世凯, 倪乐意. 长江中游浅 水湖泊水生植物氮磷含量与水柱营养的关系. 水生生物学报, 2005, 29: 406-412.]

[13] Xiong Hanfeng, Huang Shikuan, Chen Zhiping et al. Accumulation features of nitrogen and phosphorus in plants of Liangzi Lake wetland. Chinese Journal of Ecology, 2007, 26: 466-470. [熊汉锋, 黄世宽,陈治平等. 梁子湖湿地植物的氮磷 积累特征. 生态学杂志, 2007, 26: 466-470.]

[14] Lei Zexiang, Xu Delan, Xie Yifa et al. Relationship between N and P contents in aquatic macrophytes, water and sediment in Taihu Lake, China. Chinese Journal of Plant Ecology, 2008, 32: 402-407. [雷泽湘, 徐德兰, 谢贻发等. 太湖水生植 物氮磷与湖水和沉积物氮磷含量的关系. 植物生态学报, 2008, 32: 402-407.]

[15] Lu Jing, Zhou Hongxia, Tian Guangyu et al. Nitrogen and phosphorus contents in 44 wetland species from the Lake Erhai Basin. Acta Ecologica Sinica, 2011, 31: 709-715. [鲁静, 周虹霞, 田广宇等. 洱海流域 44 种湿地植物的氮磷含量特 征. 生态学报, 2011, 31: 709-715.]

[16] Xing W, Wu HP, Hao BB et al. Stoichiometric characteristics and responses of submerged macrophytes to eutrophication in lakes along the middle and lower reaches of the Yangtze River. Ecological Engineering, 2013, 54: 16-21. DOI : 10.1016/ j. ecoleng.2013.01.026.

[17] Wang Sumin, Dou Hongshen eds. A directory of lakes in China. Beijing: Science Press, 1998. [王苏民, 窦鸿身. 中国湖 泊志. 北京:科学出版社, 1998.]

[18] Sun S, Zhang C. Nitrogen distribution in the lakes and lacustrine of China. Nutrient Cycling in Agroecosystems, 2000,57 (1) : 23-31. DOI: 10.1023/A: 1009880116259 .

[19] Xiong Fei, Li Wenchao, Pan Jizheng et al. Distribution and community structure characteristics of submerged macrophytes in Lake Fuxian, Yunnan Province. Acta Botanica Yunnanica, 2006, 28: 277-282. [熊飞, 李文朝,潘继征等. 云南抚仙 湖沉水植物分布及群落结构特征. 云南植物研究, 2006, 28: 277-282.]

[20] Shen Yaqiang, Wang Haijun, Liu Xueqin. Aquatic flora and assemblage characteristics of submersed macrophytes in five lakes of the central Yunnan Province. Resources and Environment in the Yangtze Basin, 2010, 19: 111-119. [沈亚强, 王 海军, 刘学勤. 2010. 滇中五湖水生植物区系及沉水植物群落特征. 长江流域资源与环境, 2010, 19: 111-119.]

[21] Yu Qiang. Ecological stoichiometric study on vascular plants in the Inner Mongolia steppe[Dissertation]. Beijing: Institute of Botany, Chinese Academy of Sciences, 2009. [夷强. 内蒙古草原植物化学计量生态学研究 [学位论文]. 北京: 中 国科学院植物研究所, 2009.]

[22] Xie Y, Yu D, Ren B. Effects of nitrogen and phosphorus availability on the decomposition of aquatic plants. Aquatic Bota$n y, 2004, \mathbf{8 0}$ (1) : 29-37. DOI: 10.1016/j.aquabot.2004.07.002.

[23] Hu Weifang, Zhang Wenlong, Zhang Linhai et al. Stoichiometric characteristics of nitrogen and phosphorus in major wetland vegetation of China. Chinese Journal of Plant Ecology, 2014, 38: 1041-1052. [胡伟芳, 章文龙, 张林海等. 中国主 要湿地植被氮和磷生态化学计量学特征. 植物生态学报, 2014, 38: 1041-1052.]

[24] Yu Q, Elser JJ, He N et al. Stoichiometric homeostasis of vascular plants in the Inner Mongolia grassland. Oecologia, 2011, 166(1) : 1-10. DOI: 10.1007/s00442-010-1902-z.

[25] Zhang H, Wu H, Yu Q et al. Sampling date, leaf age and root size: Implications for the study of plant $\mathrm{C}: \mathrm{N}: \mathrm{P}$ stoichiometry. PLoS One, 2013, 8(4) : e60360. DOI: 10.1371/journal.pone.0060360.

[26] Li W, Cao T, Ni LY et al. Effects of water depth on carbon, nitrogen and phosphorus stoichiometry of five submersed macrophytes in an in situ experiment. Ecological Engineering, 2013, 61: 358-365. DOI : 10.1016/j.ecoleng.2013.09.028.

[27] Xing Wei, Liu Han, Liu Guihua. Ecological stoichiometry in aquatic ecosystems: Studies and applications. Plant Science Journal, 2015, 33(5): 608-619. [邢伟, 刘寒, 刘贵华. 生态化学计量学在水生态系统中的研究与应用. 植物科学 学报, $2015,33(5): 608-619$.]

[28] Xia CX, Yu D, Wang Z et al. Stoichiometry patterns of leaf carbon, nitrogen and phosphorous in aquatic macrophytes in 
eastern China. Ecological Engineering, 2014, 70: 406-413. DOI: 10.1016/j.ecoleng.2014.06.018.

[29] Li W, Cao T, Ni LY et al. Size-dependent C, N and P stoichiometry of three submersed macrophytes along water depth gradients. Environmental Earth Sciences, 2015, 74: 3733-3738. DOI: 10.1007/s12665-015-4295-9.

[30] Li Wei, He Liang, Zhu Tianshun et al. Distribution and leaf C, N, P stoichiometry of Vallisneria natans in response to various water depths in a large mesotrophic lake, Lake Erhai, China. J Lake Sci, 2014, 26(4) : 585-592. DOI: 10.18307/ 2014.0413. [ 李威, 何亮, 朱天顺等. 洱海苦草(Vallisneria natans) 水深分布和叶片 C、N、P 化学计量学对不同水深 的响应. 湖泊科学, 2014, 26(4) : 585-592.]

[31] Li Wei, Cao Te, Zhang Xiaolin et al. Interspecific and seasonal variations of phosphorus content in submersed macrophytes in Erhai Lake. Research of Environmental Sciences, 2015, 28(6) : 877-882. [李威, 曹特, 张霄林等. 洱海常见沉水植 物磷含量的种间差异及季节变化特征研究. 环境科学研究, 2015, 28(6) : 877-882.]

[32] Fu Hui, Zhong Jiayou, Yuan Guixiang et al. Sources and structures of functional traits variations in submersed macrophytes: A case of Potamogeton maackianus. J Lake Sci, 2015, 27(3): 429-435. DOI: 10.18307/2015.0309. [符辉, 钟 家有, 袁桂香等. 沉水植物功能性状变异的来源与结构一以微齿眼子菜 (Potamogeton maackianus) 为例. 湖泊科 学, 2015, 27(3): 429-435.]

[33] Fu H, Yuan GX, Zhong JY et al. Environmental and ontogenetic effects on intraspecific trait variation of a macrophyte species across five ecological scales. PLoS One, 2013, 8: e62794. DOI 10.1371/journal.pone.0062794.

[34] Dai Quanyu, Gao Licun, Zhuang Dadong. The vegetation and the trace elements of the aquatic plants in Yunnan Lake Fuxian. Transactions of Oceanology and Limnology, 1983, (1) : 52-58. [ 戴全裕, 高礼存, 庄大栋. 云南抚仙湖的水生植被 及其微量元素. 海洋湖沼通报, 1983, (1):52-58.]

[35] Li Yinxi, Liu Hong, Lu Ya et al. Preliminary studies on eutrophication in Lake Fuxian. J Lake Sci, 2003, 15(3) : 285288. DOI: 10.18307/2003.0315. [李荫胥,刘红,陆娅等. 抚仙湖富营养化初探. 湖泊科学, 2003, 15(3): 285-288.]

[36] Pan Jizheng, Xiong Fei, Li Wenchao et al. Spatial-temporal dynamic changes of the water transparency and their influencing factors in Lake Fuxian, Yunnan Province. J Lake Sci, 2008, 20(5) : 681-686. DOI:10.18307/2008.0519. [潘继征, 熊飞,李文朝等. 云南抚仙湖透明度的时空变化及影响因子分析. 湖泊科学, 2008, 20(5) : 681-686.]

[37] Gao Wei, Chen Yan, Xu Min et al.Trend and driving factors of water quality change in Lake Fuxian (1980 - 2011).J Lake Sci, 2013, 25(5) : 635-642. DOI: 10.18307/2013.0503. [高伟, 陈岩, 徐敏等. 抚仙湖水质变化 (1980-2011 年) 趋势与驱动力分析. 湖泊科学, 2013, 25(5): 635-642.]

[38] Best MD, Mantai KE. Growth of Myriophyllum: Sediment or lake water as the source of nitrogen and phosphorus. Ecology, 1978, 59(5) : 1075-1080. DOI 10.2307/1938561.

[39] Rattray MR, Howard-Williams C, Brown JMA. Sediment and water as sources of nitrogen and phosphorus for submerged rooted aquatic macrophytes. Aquatic Botany, 1991, 40(3) : 225-237. DOI 10.1016/0304-3770(91) 90060-I.

[40] Touchette BW, Burkholder JAM. Review of nitrogen and phosphorus metabolism in seagrasses. Journal of Experimental Marine Biology and Ecology, 2000, 250(1) : 133-167. DOI 10.1016/S0022-0981( 00)00195-7.

[41] Wang Xiaolei. Modern sedimentary environmental change in Yunnan Plateau Lakes—Case studies of lakes Fuxian and Dianchi[Dissertation]. Nanjing: Nanjing Normal University, 2011. [王小雷. 云南高原湖泊近现代沉积环境变化研 究——抚仙湖和滇池为例 [学位论文]. 南京:南京师范大学, 2011.]

[42] Wu Zhenbin ed. Macrophyte and aquatic ecological restoration. Beijing: Science Press, 2011. [吴振斌.水生植物与水体 生态修复. 北京:科学出版社, 2011.]

[43] Liu Zhensheng, Wang Chunsheng, Ni Jianyu et al. Ecological distribution characteristics of chlorophyll a in Lake Fuxian. Acta Ecologica Sinica, 2003, 23: 1773-1780. [刘镇盛, 王春生, 倪建宇等. 抚仙湖叶绿素 a 的生态分布特征. 生态学 报, 2003, 23: 1773-1780.]

[44] Smith CS, Adams MS. Phosphorus transfer from sediments by Myriophyllum spicatum. Limnology and Oceanography, 1986, 31(6) : 1312-1321. DOI 10.4319/lo.1986.31.6.1312. 